\title{
Pediatric Hepatocellular Carcinoma, a Single Center Study from the South of Iran: Case Series
}

\author{
Bita Geramizadeh,,${ }^{1,2,}$ Ali Kashkooe, ${ }^{2,3}$ Ali Bahador, ${ }^{4}$ Seyed Mohsen Dehghani, ${ }^{5}$ Alireza Shamsaeefar, ${ }^{4}$ \\ Kurosh Kazemi, ${ }^{4}$ and Seyed Ali Malekhosseini ${ }^{4}$ \\ ${ }^{1}$ Transplant Research Center, Shiraz University of Medical Sciences, Shiraz, Iran \\ ${ }^{2}$ Department of Pathology, Shiraz University of Medical Sciences, Shiraz, Iran \\ ${ }^{3}$ Student Research Committee, Shiraz University of Medical Sciences, Shiraz, Iran \\ ${ }^{4}$ Department of Hepatobiliary and Liver Transplant Surgery, Shiraz University of Medical Sciences, Shiraz, Iran \\ ${ }^{5}$ Department of Pediatrics, Shiraz University of Medical Sciences, Shiraz, Iran \\ "Corresponding author: Bita Geramizadeh, Transplant Research Center, Department of Pathology, Shiraz University of Medical Sciences, Shiraz, Iran. Tel/Fax: +98-7136473238, \\ E-mail: geramib@gmail.com
}

Received 2017 April 17; Revised 2017 July 16; Accepted 2017 July 22.

\begin{abstract}
Background: Hepatocellular carcinoma is a rare tumor in children, thus, there are not many studies regarding clinicopathologic findings of this tumor and no report regarding this tumor in this age group from Iran.

objectives: In this study, we tried to find out the clinicopathologic findings including outcome of hepatocellular carcinoma in the patients under the age of 18 .

Methods: During the last 10 years (2005 - 2016), we collected all hepatocellular carcinoma cases in the affiliated hospitals of Shiraz University of Medical Sciences (as the largest referral center in the South of Iran and the only center of pediatric liver transplantation in the whole country) from the archives of Pathology department. Next all clinical data were subsequently extracted from the patients' hospital charts.

Results: We collected 30 cases of hepatocellular carcinoma with the age range of 9 months to 18 years with no significant sex preference. All of the patients, except 3, showed abnormal levels of AFP. The most common underlying cause of liver tumorigenesis was type I tyrosinemia.

Conclusions: Hepatocellular carcinoma in children is a rare tumor and is mostly secondary to an underlying liver disease, which is tyrosinemia in our center. Hepatitis B related hepatocellular carcinoma is rare in our country, which seems to be related to successful early neonatal vaccination against this viral disease. This tumor has a poor outcome in children and without liver transplantation, has a very short survival rate.
\end{abstract}

Keywords: Hepatocellular Carcinoma, Pediatric

\section{Background}

Hepatocellular carcinoma (HCC) is the second most common pediatric liver tumor and accounts for 30\% of hepatic malignancies in this age group and $0.5 \%$ of all childhood malignancies (1). Overall, HCC in the pediatric age group is rare and much less common than adults (2). HCC is more common after the age of 10 and is the most common hepatic malignancy in adolescents $(3,4)$. Most of the HCCs diagnosed before the age of 10 are secondary to an underlying disease such as hepatitis B related cirrhosis and metabolic diseases like tyrosinemia (5). In this study we have investigated cases of hepatocellular carcinoma in the pediatric age group (under 18 years of age) during the last 10 years in our institution to find out the clinicopathologic characteristics of hepatocellular carcinoma in the pediatric age group in the largest referral center of pediatric hepatobiliary surgery in the South of Iran.

\section{Methods}

In the last 10 years (2005 - 2016), all of the cases of HCC in the pediatric age group ( $<18$ years of age) have been extracted from the archives of the pathology department of the affiliated hospitals of Shiraz University of Medical Sciences. During these years we found 30 cases of HCCs in the patients of the pediatric age group removed in these years. We also investigated the clinical chart of the patients to find out more about the clinicopathologic features of the disease.

\section{Results}

During the last 10 years, we found 30 cases of HCC removed in the patients below the age of 18. Among these 33 cases, there were 16 boys and 14 girls $(\mathrm{M} / \mathrm{F}=1.14 / 1)$. The youngest patient was 9 months old and the oldest, 18 years 
(Mean $=8.99 \pm 5.2)$. Twenty patients $(66 \%)$ were affected from liver cirrhosis. Fifteen (50\%) cases showed multiple nodules of HCC, $14(46.6 \%)$ cases have been located in the left lobe of the liver, and 10 (33.3\%) cases in right. Three patients were presented with the fibrolamellar variant, all the others have been well differentiated HCC, and no case of moderate to poorly differentiated HCC has been referred to our hospital. The most common underlying cause of cirrhosis in 18 (60\%) cases has been tyrosinemia. There have been 7 patients with no underlying cirrhosis and in this pediatric age group only 1 of the 23 cirrhotic patients was cryptogenic with no known underlying cause of cirrhosis. Nineteen patients have been transplanted. The largest HCC has been $17.7 \mathrm{~cm}$ and the mean tumor size was $5 \pm 5.1 \mathrm{~cm}$ (range $0.5-20 \mathrm{~cm}$ ). Most of our patients $(n=27 / 30,90 \%$ ) had increased levels of AFP, i.e. higher than $5 \mathrm{IU} / \mathrm{L}$ with the range of $620 \pm 1048.7 \mathrm{IU} / \mathrm{L}$. Among the patients, 21 patients are alive and completely well, most of which have been transplanted i.e. $16(84.2 \%)$ patients out of 19 transplanted patients are well and alive, however, only 5 (45.45\%) out of 11 nontransplanted patients are alive. Table 1 shows the details of clinicopathologic findings of the patients.

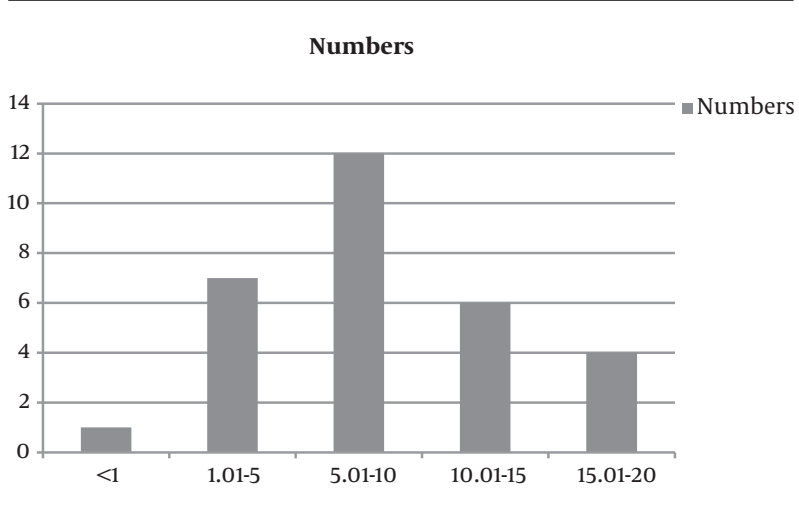

Figure 1. Histogram of Age Distribution of 30 Patients with HCC

\section{Discussion}

Hepatocellular carcinoma is considered as a rare pediatric tumor, however, it is the second most common malignant liver tumor in this age group $(6,7)$. Most of HCCs in the pediatric age group has been reported in adolescents after 10 years of age, and occurrence of this tumor in young children is almost always associated with an underlying metabolic or viral liver disease $(7,8)$. There have not been any studies regarding HCC in the pediatric age group from Iran. All of the previous reports regarding HCC from Iran have been in the adult age group. Our center is the largest referral center of hepatobiliary surgery in the South of Iran

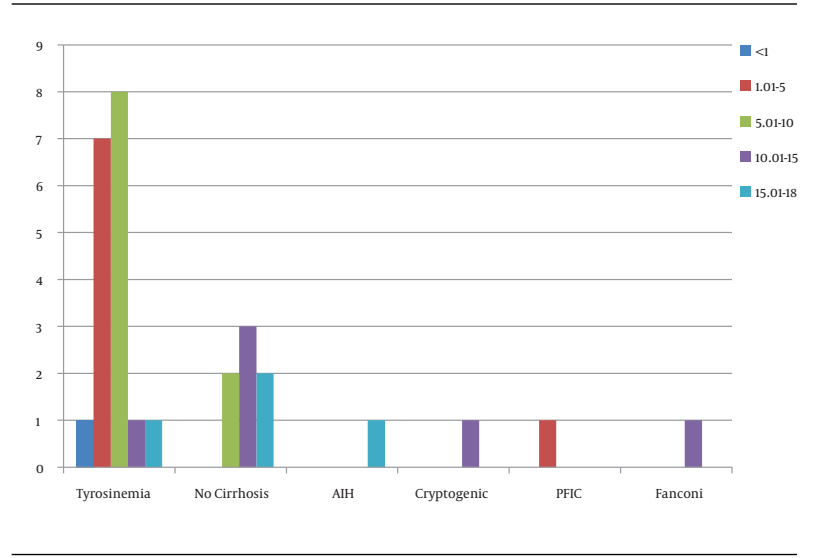

Figure 2. Age Distribution According to the Underlying Cause of HCC

and also the only center for pediatric liver transplantation in the country; therefore, we decided to retrieve all the cases of HCCs in the children below the age of 18 in our affiliated hospitals to find out about different clinicopathologic findings of these cases.

In the last 10 years, there have been 30 cases of HCC in the patients below the age of 18 years. Although this tumor is more common in boys, the difference in boys and girls was not significant $(\mathrm{M} / \mathrm{F}=1.14 / 1)$. Most of our cases have been in cirrhotic livers with known underlying cause. The most common underlying cause in our center has been tyrosinemia. Tyrosinemia is an important cause of pediatric HCC, especially in the untreated patients (8). However, we had 1 case of PFIC (Progressive familial intrahepatic cholestasis). There have been rare reports regarding the occurrence of HCC in patients with PFIC, which emphasizes on the risk of HCC in the patients with defects in bile export proteins, i.e. PFIC $(9,10)$.

One of our cases has been autoimmune hepatitis (AIH), under treatment that found to have HCC as well as AIH. The occurrence of HCC in AIH, especially in a young patient (17year-old), is a rare event; however, it should be kept in mind (11).

One of our cases has been cirrhotic secondary to Alagille syndrome, which has undergone liver transplantation. There have been well-documented reports of HCC in Alagille, however, it is very rare (12).

There have been 3 cases with no underlying disease and fibrolamellar variant of HCC, which is known to occur in healthy livers of young and adolescents without cirrhosis. It used to be considered as a type of HCC with a better prognosis; however, case-control studies failed to show prognostic difference between HCC and its fibrolamellar variant $(4,13)$. Our patients have been 15,11 , and 16 years of age, 2 of which were unfortunately dead at the time of study. All of the other cases have been well-differentiated hepatocel- 
Table 1. Different Clinicopathologic Findings of the 30 Cases of HCC in the Patients Below the Age of 18 Years

\begin{tabular}{|c|c|c|c|c|c|c|c|c|c|c|c|}
\hline No. & Age, $y$ & Sex & Location & Number & $\begin{array}{l}\text { Size, cm (Largest } \\
\text { Diameter) }\end{array}$ & $\begin{array}{l}\text { Underlying } \\
\text { Disease }\end{array}$ & Cirrhosis & $\begin{array}{c}\operatorname{AFP}(\mathbf{I U} / \mathbf{L}) \mathbf{N l}=5 \\
\mathbf{I U} / \mathbf{L}\end{array}$ & Liver Transplant & Follow Up & $\begin{array}{l}\text { Histologic } \\
\text { Subtype }\end{array}$ \\
\hline 1 & 6 & Male & Diffuse & Multiple & 2.5 & Tyrosinemia & + & 12 & + & Alive & Well diff HCC \\
\hline 2 & 10 & Male & Right lobe & 1 & 2 & Tyrosinemia & + & 251.6 & . & Died & Well diff HCC \\
\hline 3 & 17 & Male & Right lobe & 1 & 2 & $\begin{array}{l}\text { Autoimmune } \\
\text { hepatitis }\end{array}$ & - & 10 & + & $\begin{array}{l}\text { Alive } 2 \text { years post } \\
\mathrm{Tx}\end{array}$ & Well diff HCC \\
\hline 4 & 14 & Female & Left lobe & Multiple & 4 & Tyrosinemia & + & 51.2 & + & $\begin{array}{l}\text { Alive } 4 \text { years post } \\
\mathrm{Tx}\end{array}$ & Well diff HCC \\
\hline 5 & 15 & Female & Right lobe & 1 & 12 & . & . & 15 & . & Died & Fibrolamellar HCC \\
\hline 6 & 3 & Male & Left lobe & 1 & 1 & PFIC & + & 8.3 & + & $\begin{array}{l}\text { Alive, } 2 \text { years post } \\
\text { Tx }\end{array}$ & Well diff HCC \\
\hline 7 & 5 & Female & Left lobe & Multiple & 8 & Tyrosinemia & + & 400 & + & $\begin{array}{l}\text { Alive } 4 \text { years post } \\
\text { Tx }\end{array}$ & Well diff HCC \\
\hline 8 & 4 & Female & Right lobe & 1 & 1 & Tyrosinemia & + & 553 & + & $\begin{array}{l}\text { Alive } 3 \text { years post } \\
\text { Tx }\end{array}$ & Well diff HCC \\
\hline 9 & 5 & Female & Right lobe & 1 & 3 & Tyrosinemia & + & 4000 & + & Alive 1 year post $\mathrm{Tx}$ & Well diff HCC \\
\hline 10 & 17 & Male & Diffuse & Multiple & 8 & Tyrosinemia & + & 1000 & - & Died & Well diff HCC \\
\hline 11 & 5 & Male & Left lobe & 2 & 0.5 & Tyrosinemia & + & 1.9 & + & $\begin{array}{l}\text { Alive, } 2 \text { years post } \\
\text { Tx }\end{array}$ & Well diff HCC \\
\hline 12 & 15 & Male & Left lobe & 1 & 2 & Unknown & + & 1000 & + & Died & Well diff HCC \\
\hline 13 & $<1$ & Male & Right lobe & 3 & 1.7 & Tyrosinemia & + & 12 & + & $\begin{array}{l}\text { Alive, } 2.5 \text { years post } \\
\text { Tx }\end{array}$ & Well diff HCC \\
\hline 14 & 10 & Female & Left lobe & 1 & 8 & - & - & 13 & - & Alive & Well diff HCC \\
\hline 15 & 1 & Female & right lobe & 2 & 1.2 & Tyrosinemia & + & 50 & + & $\begin{array}{l}\text { Died, } 15 \text { month } \\
\text { post Tx }\end{array}$ & Well diff HCC \\
\hline 16 & 11 & Male & $\begin{array}{l}\text { Both lobes and } \\
\text { hilum }\end{array}$ & 2 & 12.5 & - & - & 45 & + & $\begin{array}{l}\text { Died } 7 \text { months } \\
\text { post Tx }\end{array}$ & Fibrolamellar HCC \\
\hline 17 & 8 & Male & Both lobes & Multiple & & Allagile Sx & + & 1650 & - & Alive & Well diff HCC \\
\hline 18 & 2 & Male & Left lobe & 1 & 2 & Tyrosinemia & + & 619 & + & Alive & Well diff HCC \\
\hline 19 & 1 & Male & Left lobe & 1 & 1 & Tyrosinemia & + & 751 & + & Alive, 1 year post Tx & Well diff HCC \\
\hline 20 & 11 & Male & Both lobes & Multiple & 3.7 & - & + & 267 & . & Died & Well diff HCC \\
\hline 21 & 18 & Female & Left lobe & 1 & 20 & . & - & 1.4 & + & $\begin{array}{l}\text { Alive, } 3 \text { years post } \\
\text { Tx }\end{array}$ & $\begin{array}{l}\text { Well differentiated } \\
\text { HCC }\end{array}$ \\
\hline 22 & 10 & Female & Left Lobe & 2 & 17.7 & Tyrosinemia & + & 250 & + & $\begin{array}{l}\text { Alive, } 2 \text { years post } \\
\text { TX }\end{array}$ & Well diff HCC \\
\hline 23 & 8 & Male & Left lobe & 1 & 2.4 & Tyrosinemia & + & 671 & + & $\begin{array}{l}\text { Alive, } 3 \text { years post } \\
\text { Tx }\end{array}$ & Well diff HCC \\
\hline 24 & 7 & Female & Right lobe & 1 & 1.5 & Tyrosinemia & + & 908 & + & $\begin{array}{l}\text { Alive, } 3 \text { years post } \\
\mathrm{Tx}\end{array}$ & Well diff HCC \\
\hline 25 & 6 & Female & Right lobe & Multiple & 18 & Tyrosinemia & + & 2000 & + & $\begin{array}{l}\text { ALive, 1 year post } \\
\text { Tx }\end{array}$ & Well diff HCC \\
\hline 26 & 10 & Female & Right lobe & 1 & 9 & - & - & 23 & - & Alive & Well diff HCC \\
\hline 27 & 16 & Female & Right and Left lobe & Multiple & 6 & - & - & 4.4 & + & $\begin{array}{l}\text { Alive, } 2 \text { years post } \\
\mathrm{Tx}\end{array}$ & Fibrolamellar HCC \\
\hline 28 & 8 & Male & Left lobe & Multiple & 2.4 & Tyrosinemia & + & 3980 & + & $\begin{array}{l}\text { Alive } 2 \text { years post } \\
\mathrm{Tx}\end{array}$ & Well diff HCC \\
\hline 29 & 7 & Male & Left lobe & 1 & 6 & Tyrosinemia & + & 34 & - & Died & Well diff HCC \\
\hline 30 & 13 & Female & Left lobe & Multiple & 8 & Fanconi & - & 45 & . & Died & Well diff HCC \\
\hline
\end{tabular}

lular carcinoma.

Many of the previous studies have reported chronic hepatitis B related cirrhosis as the most common underlying cause of pediatric HCC (14), however, we didn't have any case of HBV related cirrhosis in these 30 cases of pediatric HCC. We believe it is due to extensive and successful vaccination in Iran and significant decrease in the number of HBVs in the current generation of pediatric age group. With $0.96 \%$ of HBs Ag carriage, Iran is now considered as a low endemicity country for chronic infection with HBV (15).
Diagnosis of HCC is based on clinicopathologic and radiologic findings; however, AFP plays an important role in the early diagnosis and follows up of the patients with cirrhosis (16). Most of our cases had elevated AFP, which most of them were significantly high, therefore, our study confirms the value of AFP in the diagnosis of HCC even in the pediatric age group (17).

As a conclusion, HCC should be considered as a rare pediatric tumor in Iran, which is most commonly secondary to cirrhosis due to metabolic diseases specially tyrosinemia. This tumor has a poor prognosis and without liver 
transplantation has a short survival.

\section{Footnotes}

Financial Disclosure: There is no financial disclosure. Conflict of Interest: There is no conflict of interest. Funding/Support: This project has been conducted under the support of research project No: 12388, Shiraz University of Medical Sciences

\section{References}

1. Lau CS, Mahendraraj K, Chamberlain RS. Hepatocellular Carcinoma in the Pediatric Population: A Population Based Clinical Outcomes Study Involving 257 Patients from the Surveillance, Epidemiology, and End Result (SEER) Database (1973-2011). HPB Surg. 2015;2015:670728. doi: 10.1155/2015/670728. [PubMed: 26663981].

2. Wichajarn K, Kosalaraksa P, Wiangnon S. Incidence of hepatocellular carcinoma in children in Khon Kaen before and after national hepatitis B vaccine program. Asian Pac J Cancer Prev. 2008;9(3):507-9. [PubMed: 18990029].

3. Litten JB, Tomlinson GE. Liver tumors in children. Oncologist 2008;13(7):812-20. doi: 10.1634/theoncologist.2008-0011. [PubMed: 18644850].

4. Geramizadeh B, Bahador A, Foroutan HR, Banani A, Nikeghbalian $S$, Malek-Hosseini SA. Pathology of pediatric liver tumors, a single center experience from south of Iran. Indian J Pathol Microbiol. 2010;53(3):422-6. doi: 10.4103/0377-4929.68258. [PubMed: 20699496].

5. Chang MH. Hepatocellular carcinoma in children. Zhonghua Min Guo Xiao Er Ke Yi Xue Hui Za Zhi. 1998;39(6):366-70. [PubMed: 9926508].

6. Moore SW, Hesseling PB, Wessels G, Schneider JW. Hepatocellular carcinoma in children. Pediatr Surg Int. 1997;12(4):266-70. doi: 10.1007/BF01372147. [PubMed: 9099643].

7. Walther A, Tiao G. Approach to pediatric hepatocellular carcinoma. Clinical Liver Disease. 2013;2(5):219-22. doi:10.1002/cld.260.

8. Bahador A, Dehghani SM, Geramizadeh B, Nikeghbalian S, Bahador M, Malekhosseini SA, et al. Liver Transplant for Children With Hepatocellular Carcinoma and Hereditary Tyrosinemia Type 1. Exp Clin
Transplant. 2015;13(4):329-32. doi: 10.6002/ect.2013.0158. [PubMed: 24679101].

9. Berumen J, Feinberg E, Todo T, Bonham CA, Concepcion W, Esquivel C. Complications following liver transplantation for progressive familial intrahepatic cholestasis. Dig Dis Sci. 2014;59(11):2649-52. doi: 10.1007/s10620-014-3220-5. [PubMed: 24879297].

10. Knisely AS, Strautnieks SS, Meier Y, Stieger B, Byrne JA, Portmann BC, et al. Hepatocellular carcinoma in ten children under five years of age with bile salt export pump deficiency. Hepatology. 2006;44(2):478-86. doi:10.1002/hep.21287. [PubMed:16871584].

11. Geramizadeh B, Nikeghbalian S, Shamsaifar A, Kazemi K, Malekhosseini SA. Hepatocellular carcinoma in two patients with autoimmune hepatitis, a single center experience and review of the literature. Hepat Mon. 2013;13(4):e7957. doi: 10.5812/hepatmon.7957. [PubMed: 23805159].

12. Bhadri VA, Stormon MO, Arbuckle S, Lam AH, Gaskin KJ, Shun A. Hepatocellular carcinoma in children with Alagille syndrome. J Pediatr Gastroenterol Nutr. 2005;41(5):676-8. doi: 10.1097/01.mpg.0000179759.60048.c4. [PubMed: 16254531].

13. Katzenstein HM, Krailo MD, Malogolowkin MH, Ortega JA, Qu W, Douglass EC, et al. Fibrolamellar hepatocellular carcinoma in children and adolescents. Cancer. 2003;97(8):2006-12. doi: 10.1002/cncr.11292. [PubMed: 12673731].

14. Czauderna P, Mackinlay G, Perilongo G, Brown J, Shafford E, Aronson D, et al. Hepatocellular carcinoma in children: results of the first prospective study of the International Society of Pediatric Oncology group. J Clin Oncol. 2002;20(12):2798-804. doi: 10.1200/JCO.2002.06.102. [PubMed:12065556].

15. Salehi-Vaziri M, Sadeghi F, Almasi Hashiani A, Gholami Fesharaki M, Alavian SM. Hepatitis B Virus Infection in the General Population of Iran: An Updated Systematic Review and Meta-Analysis. Hepat Mon. 2016;16(4):e35577. doi:10.5812/hepatmon.35577. [PubMed: 27257428].

16. Chen JC, Chen CC, Chen WJ, Lai HS, Hung WT, Lee PH. Hepatocellular carcinoma in children: clinical review and comparison with adult cases. J Pediatr Surg. 1998;33(9):1350-4. doi: 10.1016/S00223468(98)90005-7. [PubMed: 9766351].

17. Kashyap R, Jain A, Nalesnik M, Carr B, Barnes J, Vargas HE, et al. Clinical significance of elevated alpha-fetoprotein in adults and children. Dig Dis Sci. 2001;46(8):1709-13. doi: 10.1023/A:1010605621406. [PubMed: 11508671]. 